DOI: $10.5216 /$ cab.v13i3.8549

\title{
EFICÁCIA DO “TETRA-TEST” COMO FERRAMENTA DE GESTÃO DA QUALIDADE DO LEITE CRU REFRIGERADO
}

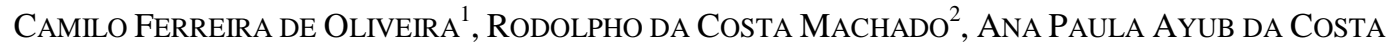 \\ BARBON $^{1}$, LUIZ FRANCISCO PRATA ${ }^{3}$
}

\footnotetext{
${ }^{1}$ Pós-graduando da Faculdade de Ciências Agrárias e Veterinárias da Universidade Estadual Paulista, Jaboticabal, SP, Brasil.

${ }^{2}$ Graduando da Faculdade de Ciências Agrárias e Veterinárias da Universidade Estadual Paulista, Jaboticabal, SP, Brasil.

${ }^{3}$ Professor Doutor da Faculdade de Ciências Agrárias e Veterinárias da Universidade Estadual Paulista, Jaboticabal, SP, Brasil lfprata@fcav.unesp.br
}

\begin{abstract}
Avaliou-se a eficácia de uma nova ferramenta para a seleção e gestão da qualidade do leite cru refrigerado. Foram analisadas 374 amostras individuais de leite refrigerado (produtor) e 125 amostras de leite de conjunto desses mesmos produtores (bocas de tanques do veículo transportador). As amostras individuais foram submetidas à prova rápida de redução em tubos - "Tetra-test", com o objetivo de estimar a carga bacteriana e a microbiota predominante, enquanto as de conjunto foram submetidas à contagem padrão em placas (CPP), como método de referência. O "Tetra-test" mostrou-se eficaz na seleção ("screening") da matéria-prima, evidenciando redução em tempo recorde variando de $5 \mathrm{~min}$ a $2 \mathrm{~h}$ para a maioria

$(82,4 \%)$ das amostras com CBT $>10^{6} \mathrm{UFC} / \mathrm{mL}$, possibilitando avaliação da qualidade do leite cru refrigerado e sua utilização como ferramenta de gestão na própria seleção ou na escolha de intervenções em função do problema detectado, uma vez que seus resultados possibilitaram informações complementares sobre as características da microbiota dominante. Grande parte das amostras não atendeu aos requisitos da IN 51, com 211 delas $(56,4 \%)$ denotando elevada carga microbiana e matéria-prima de qualidade ruim. Os psicrotróficos ainda não se constituíram em deteriorantes principais do leite cru refrigerado, mas estiveram presentes em $76,8 \%$ das amostras.
\end{abstract}

PALAVRAS-CHAVE: gestão da qualidade; leite cru refrigerado; microrganismos psicrotróficos; qualidade.

\section{EFFECTIVENESS OF TETRA-TEST AS A TOOL FOR QUALITY MANAGEMENT OF REFRIGERATED RAW MILK}

\section{ABSTRACT}

The effectiveness of a new management tool for screening refrigerated raw milk quality in a dairy industry is provided. Three hundred and seventy-four samples of raw milk from individual producers and 125 samples from bulk milk carriers from the same producers were analyzed. Producers' samples underwent a fast tube reduction test, or Tetra-Test, to estimate total bacteriological charge and their predominant microbiota. Bulk milk samples underwent standard plate count (SPC) as reference method. Tetra-test was effective in screening and assessing the microbiological quality of refrigerated raw milk, since $82.4 \%$ of samples with more than $10^{6} \mathrm{UFC} / \mathrm{mL}$ were readily detected ( 5 minutes to $2 \mathrm{~h}$ ). The test may be employed as a management tool either in screening or in interventions on the detected problem. In fact, its results provided complementary information on the characteristics of dominant microbiota. Most samples failed in compliance to IN 51 requirements. Further, 211 samples (56.4\%) showed high microbial charge and, consequently, poor quality raw milk. Psychrotrophic groups were not yet the main degrading factors of cooled raw milk, albeit present in $76.8 \%$ of samples.

KEYWORDS: psychrotrophic groups; quality; quality management; refrigerated raw milk. 


\section{INTRODUÇÃO}

Qualidade do leite é tema complexo devido à diversidade dos sistemas de produção, tornando difícil a implementação eficaz de normas produtivas relacionadas à segurança e inocuidade do produto. No Brasil, em 2007, a produção de leite foi estimada em 26,7 bilhões de litros. Segundo projeções da FAO (Food and Agriculture Organization), o consumo de lácteos aumentará significativamente até 2030, obrigando a cadeia produtiva a profissionalizar-se, com ferramentas técnicas para aumentar a produtividade de forma sustentável.

Atualmente, o leite que chega às indústrias é de baixa qualidade, possivelmente, devido às deficiências na sua estocagem e transporte. Evidências de que o leite produzido no Brasil nem sempre apresenta a qualidade desejada são antigas, mas somente em 2002 a Instrução Normativa 51 estabeleceu inovações, entre elas a estocagem refrigerada desde a produção e a definição de um padrão de qualidade para leite cru refrigerado (máximo de $1,0 \times 10^{6} \mathrm{UFCmL}^{-1}$ ); no entanto, diferentemente do que ocorreu em outros países, não estabeleceu a necessária adequação da metodologia analítica para a comprovação dessa qualidade quando do recebimento diário da matéria-prima (BRASIL, 2002).

Algumas mudanças já se mostram significativas, como a refrigeração e estocagem do leite na fazenda e a coleta a granel, as quais mudaram também os problemas e as necessidades relativas à manutenção e comprovação da qualidade e do estado de conservação do produto recebido pelas indústrias (BRASIL, 2002). VALLIN et al. (2009) mostraram que a simples implementação de boas práticas de higiene na ordenha, por si só, foi capaz de melhorar a qualidade do leite. Entretanto, na maioria das propriedades, a temperatura de refrigeração oscila entre 5 e $10^{\circ} \mathrm{C}$, o que configura um "resfriamento marginal", contribuindo para a multiplicação de microrganismos, principalmente os psicrotróficos (SANTANA et al., 2001; ARCURI et al., 2008; MARTINS et al., 2008). IZIDORO (2008) salientou o quão deletérios podem ser os efeitos de um resfriamento marginal ao permitir a multiplicação de uma microbiota de características mistas mesófilas/psicrotróficas. Além dos problemas aventados, é comum observar-se, na prática, em algumas regiões e principalmente na estação chuvosa, tempo de estocagem acima do recomendado (48h) e uso de caminhões inadequados para o transporte do produto.

DIAS et al. (2007), na região de Araçatuba (SP), verificaram que 55\% dos tanques de expansão apresentaram temperatura acima do permitido, observando que apenas $45 \%$ das amostras situavamse dentro dos limites da legislação. NERO et al. (2005) revelaram a incapacidade de cumprir as normas estabelecidas na IN 51, especialmente quanto ao padrão microbiológico, com $48,6 \%$ das amostras em desacordo, em áreas produtoras de leite de quatro estados no Brasil. Os autores concluíram que algumas áreas poderiam enfrentar dificuldades de adequação, uma vez que os resultados mostraram alta frequência de amostras com elevada contaminação por mesófilos aeróbios.

A temperatura e o período de armazenamento do leite determinam a intensidade de desenvolvimento das diversas espécies contaminantes (ARCURI et al., 2008; IZIDORO, 2008; SOARES et al., 2008). O emprego adequado de baixas temperaturas, quando associadas a boas práticas higiênicas, inibe ou reduz a multiplicação da maioria das bactérias e diminui a atividade de enzimas degradativas, mas pode também ser seletiva para espécies psicrotróficas. Esses microrganismos constituem o grupo de maior potencial deteriorativo para o leite e derivados estocados sob refrigeração. DIAS et al. (2007) demonstram que as contagens de psicrotróficos variaram de $1,0 \times 10^{2}$ a $7,2 \times 10^{7}$ $\mathrm{UFCmL}^{-1}$, com as maiores estimativas verificadas em tanques cuja temperatura estava no limite superior $\left(4^{\circ} \mathrm{C}\right)$ ou mais alta $\left(8^{\circ} \mathrm{C}\right)$, confirmando que a faixa entre 7 e $10^{\circ} \mathrm{C}$ atua favoravelmente a esse grupo.

Em decorrência dessas mudanças, os métodos até então utilizados para a avaliação do leite recebido (redutase) deixaram de ser eficazes, tanto na qualidade da resposta esperada e sua necessária confiabilidade, quanto como contribuição às ferramentas de gestão que serão irreversivelmente adotadas, embora continuem sendo utilizados diariamente. Nesse aspecto, sequer as indústrias encontram-se preparadas para essas mudanças. Apesar do conhecimento e existência de normas e padrões, a aceitação da matéria-prima ainda se faz ou por métodos obsoletos, ou por meio de triagem mínima de amostras coletivas (como acidez, gordura, crioscopia e teste para resíduos de inibidores), impossibilitando que se conheça a verdadeira realidade dos fornecedores (parceiros) e se possa intervir sobre essa realidade.

PRATA (2007), amparado pela literatura, principalmente pelo reconhecimento internacional da técnica de Petrifilm ${ }^{\mathrm{TM}}$ (BELOTTI et al., 2002; MAHMOUD \& GHALY, 2004) e da descrição do "psycro-fast-test"(CRAVEN et al., 1994), propôs, para essa finalidade, a realização de um teste rápido de redução em tubos - "Tetra-test", padronizado para avaliar a qualidade do leite cru refrigerado, como um "screening" de recepção para as amostras de 
produtores, em substituição às provas de Redução do Azul de Metileno ou da Resazurina.

O objetivo deste trabalho foi verificar a eficácia do "Tetra-test" nessas novas condições, comparativamente a testes tradicionais, visando à possibilidade de, simultaneamente, melhorar a especificidade e qualidade da resposta e constituir-se em ferramenta de gestão que possa ter utilidade na intervenção precoce quando da ocorrência de problemas.

\section{MATERIAL E MÉTODOS}

O experimento foi realizado no Laboratório de Inspeção Sanitária de Alimentos do Departamento de Medicina Veterinária Preventiva e Reprodução Animal da Faculdade de Ciências Agrárias e Veterinárias da UNESP, Campus de Jaboticabal, com a colaboração de duas indústrias de laticínios, uma processando cerca de $300.000 \mathrm{~L} /$ dia e a outra cerca de $800.000 \mathrm{~L} / \mathrm{dia}$, ambas com o intuito principal de produção de leite UAT (Ultra Alta Temperatura).

Foram colhidas e analisadas 374 amostras individuais de leite cru refrigerado (produtor) e 125 amostras de leite de conjunto (bocas de tanques de caminhões transportadores) referentes a esses mesmos produtores. Ainda nos laticínios, as amostras de conjunto foram submetidas às provas de densidade, acidez, alizarol, gordura, crioscopia, redução do azul de metileno e pesquisa de resíduos de antibióticos, de acordo com a Instrução Normativa 68 (BRASIL, 2006). Em seguida, houve a liberação das amostras de produtores correspondentes a cada boca de tanque, as quais foram acondicionadas em caixas isotérmicas contendo gelo e transportadas para o laboratório.

As amostras individuais foram submetidas à prova rápida de redução em tubos, "Tetra-test", com o objetivo de estimar a carga microbiana do leite e o tipo de microrganismo predominante em cada uma delas, isto é, de acordo com as condições de realização do teste, com utilização ou não de inibidor de Gram+, controle do tempo de redução e manutenção da temperatura entre 20 e $25^{\circ} \mathrm{C}$. Essas condições visaram possibilitar o rápido desenvolvimento de contaminantes decorrentes de deficiências higiênicas na obtenção do leite convencionalmente denominada "microbiota predominantemente Gram+", ou, na outra série, favorecer o rápido desenvolvimento de mesófilos adaptados ou a prévia seleção de psicrotróficos convencionalmente denominada "microbiota predominantemente Gram-" (PRATA, 2007).

O teste foi realizado distribuindo-se $10 \mathrm{~mL}$ de cada amostra, em duplicata (duas séries), em tubos de vidro com rosca que foram colocados em "banhomaria" a $37^{\circ} \mathrm{C}$ por cinco minutos para que a temperatura fosse igualada. Em seguida, adicionouse $1 \mathrm{~mL}$ de solução de cloreto de benzalcônio a $0,5 \%$ na primeira série, com a finalidade de inibir o desenvolvimento de Gram+ (estimativa de psicrotróficos), com homogeneização e posterior repouso. Posteriormente, adicionou-se, a ambas as séries, $1 \mathrm{~mL}$ de solução de cloreto de trifeniltetrazolium (TTC - como indicador) a $0,5 \%$ a cada tubo, com homogeneização e início da contagem do tempo. Durante toda a duração da prova os tubos devem permanecer estáticos (sem agitação ou inversão), o que possibilita verificar possível predominância de aeróbios ou anaeróbios estritos.

O teste foi conduzido sobre a bancada do laboratório, sob iluminação natural e artificial e ambiente climatizado (ar condicionado, com temperatura ambiente variando de 20 a $25^{\circ} \mathrm{C}$ ). A leitura dos tubos se iniciou aos 5 minutos após a adição do TTC, posteriormente aos 15,30 e 60 minutos e, em seguida, de hora em hora $(2,3,4$ e 5 horas). Uma última leitura foi realizada 24 horas após o início para verificar a existência de possíveis amostras que não reduziram o TTC.

Em seguida, foram realizadas as seguintes provas físico-químicas, com o objetivo de avaliar as características do leite que chega aos laticínios (BRASIL, 2006): acidez, fosfatase alcalina, teor de cloretos, presença de substâncias alcalinas e presença de água oxigenada. As amostras de conjunto foram submetidas à contagem padrão em placas para microrganismos mesófilos e facultativos viáveis Contagem Bacteriana Total (CBT) em PCA - "Plate Count Agar" (Merck cat. n. 1.05463.0500 Darmstadt, Germany) (APHA, 2001); à determinação do teor de Glicomacropeptídeo - GMP livre (FUKUDA et al, 2004) e do índice de refração do soro cúprico (BRASIL, 2006).

\section{RESULTADOS E DISCUSSÃO}

A acidez, para as amostras de produtores, variou de 12,0 a $23,0^{\circ} \mathrm{D}$, isto é, desde leite anormal e alcalino até leites ácidos, denotando desenvolvimento bacteriano e fermentação da lactose. Do total, $346(92,5 \%)$ se apresentaram dentro dos padrões normais, ou seja, no intervalo entre 14 e $18^{\circ}$ Dornic, o que significa que, comparando-se com resultados de um passado não muito longínquo, a refrigeração já presta importante colaboração na preservação da matéria-prima. Das $28(7,5 \%)$ amostras restantes, 11 apresentaram valores de acidez abaixo de $14^{\circ}$ Dornic, ou seja, com reação alcalina, representando $3,0 \%$ e denotando 
possíveis problemas sanitários de glândula mamária na origem, seja de mastites ou fase final de período de lactação. Outras 17 amostras (4,5\%) apresentaram valores acima de $18^{\circ}$ Dornic, ou seja, com acidez elevada, significando a inadequação da estocagem refrigerada, permitindo o desenvolvimento de mesófilos fermentadores de lactose, em possível associação com deficiências higiênicas de obtenção.

As amostras foram submetidas à prova da fosfatase com o intuito de caracterizá-las como sendo realmente amostras de leite cru, ou amostras de leite que foram previamente aquecidos, como é comum verificar-se no leite "spot", ou seja, normalmente um excedente de matéria-prima comercializado entre os laticínios das mais variadas e distantes localidades. Do total de amostras ditas de produtor, seis $(1,6 \%)$ apresentaram resultado negativo, possivelmente tratando-se de leite "spot", e o restante, 98,4\% efetivamente representaram leite cru. Essas seis amostras com fosfatase negativa, invariavelmente, apresentaram elevados índices de proteólise da $\kappa$-caseína, sendo que quatro delas não apresentaram redução do TTC em 24 horas.

Essa prova foi realizada em 348 das 374 amostras de leite, pois algumas amostras não tinham quantidade suficiente para a realização de todas as provas. Do total analisado, $230(66,1 \%)$ foram negativas para teor excessivo de cloretos (até $0,130 \mathrm{~g} \%), 116(33,33 \%)$ foram caracterizadas como suspeitas ou com teor de cloretos ligeiramente elevado e acima do normal (de 0,131 a $0,160 \mathrm{~g} \%$ ) e duas $(0,6 \%)$ foram positivas, isto é, com teor de cloretos acima de $0,161 \mathrm{~g} \%$. Os resultados para o teor de cloretos encontrados denotam possíveis problemas de ordem sanitária do rebanho, ou seja, uma considerável prevalência de mastite nos animais.

A Tabela 1 mostra o número de amostras que apresentaram redução do TTC em cada uma das séries em que o teste foi realizado, denominadas convencionalmente de Gram+ ou "contaminantes" e de Gram- ou "microbiota predominantemente psicrotrófica" (em função da utilização de inibidor e realização de teste em temperatura média de $22^{\circ} \mathrm{C}$ ). Esse conjunto de resultados atendeu ao objetivo de realizar uma estimativa da qualidade microbiológica do leite dos produtores das diferentes linhas de coleta, seja da carga microbiana total ou da microbiota com características psicrotróficas, possibilitando inferir sobre a importância de cada uma em situações particularizadas para, depois, comparando-se à contagem em placas das amostras de conjuntos, analisar seu comportamento ou influência.

O "Tetra-Test", que pode ser utilizado na rotina de qualquer laboratório, dependendo das condições de execução e incubação, oferece estimativas comparáveis aos resultados dos métodos tradicionais para a separação de leites de qualidade ruim e péssima quanto à estimativa total de mesófilos, à estimativa de psicrotróficos, e fornece informações sobre a microbiota dominante (se o problema é de ordem higiênica ou de seleção de psicrotróficos), além de indicar a possível presença de inibidores (Figura 1). A primeira e principal vantagem pode ser verificada pela comparação desses resultados com os da prova de Redução do Azul de Metileno realizada pelas indústrias, a qual não foi capaz de discriminar nenhuma dessas amostras em tempo inferior a 2 horas de incubação.

TABELA 1. Resultado das provas de redução do TTC ("tetra-test"), com números e respectivas porcentagens das amostras que apresentaram redução em cada tempo de leitura. Amostras de produtores, Jaboticabal, SP

\begin{tabular}{lcccc}
\hline \multirow{2}{*}{$\begin{array}{c}\text { Tempo de Redução } \\
\text { (h:min) }\end{array}$} & \multicolumn{4}{c}{ Amostras de Produtores } \\
\cline { 2 - 5 } & Microbiota Gram + "Contaminantes" & Microbiota Gram - "Psicrotrófica" \\
\cline { 2 - 5 } & Número & $\%$ & Número & $\%$ \\
\hline $0: 15$ & 34 & 9,1 & 0 & 0,0 \\
$0: 30$ & 46 & 12,3 & 3 & 0,8 \\
$1: 00$ & 74 & 19,8 & 13 & 3,5 \\
$2: 00$ & 57 & 15,2 & 40 & 10,7 \\
$3: 00$ & 38 & 10,2 & 67 & 17,9 \\
$4: 00$ & 29 & 7,7 & 61 & 16,3 \\
$5: 00$ & 46 & 12,3 & 65 & 17,4 \\
$24: 00$ & 46 & 12,3 & 113 & 30,2 \\
\hline Sem Redução $(24 \mathrm{~h})$ & 4 & 1,1 & 12 & 3,2 \\
\hline TOTAL & 374 & 100,0 & 374 & 100,0 \\
\hline
\end{tabular}




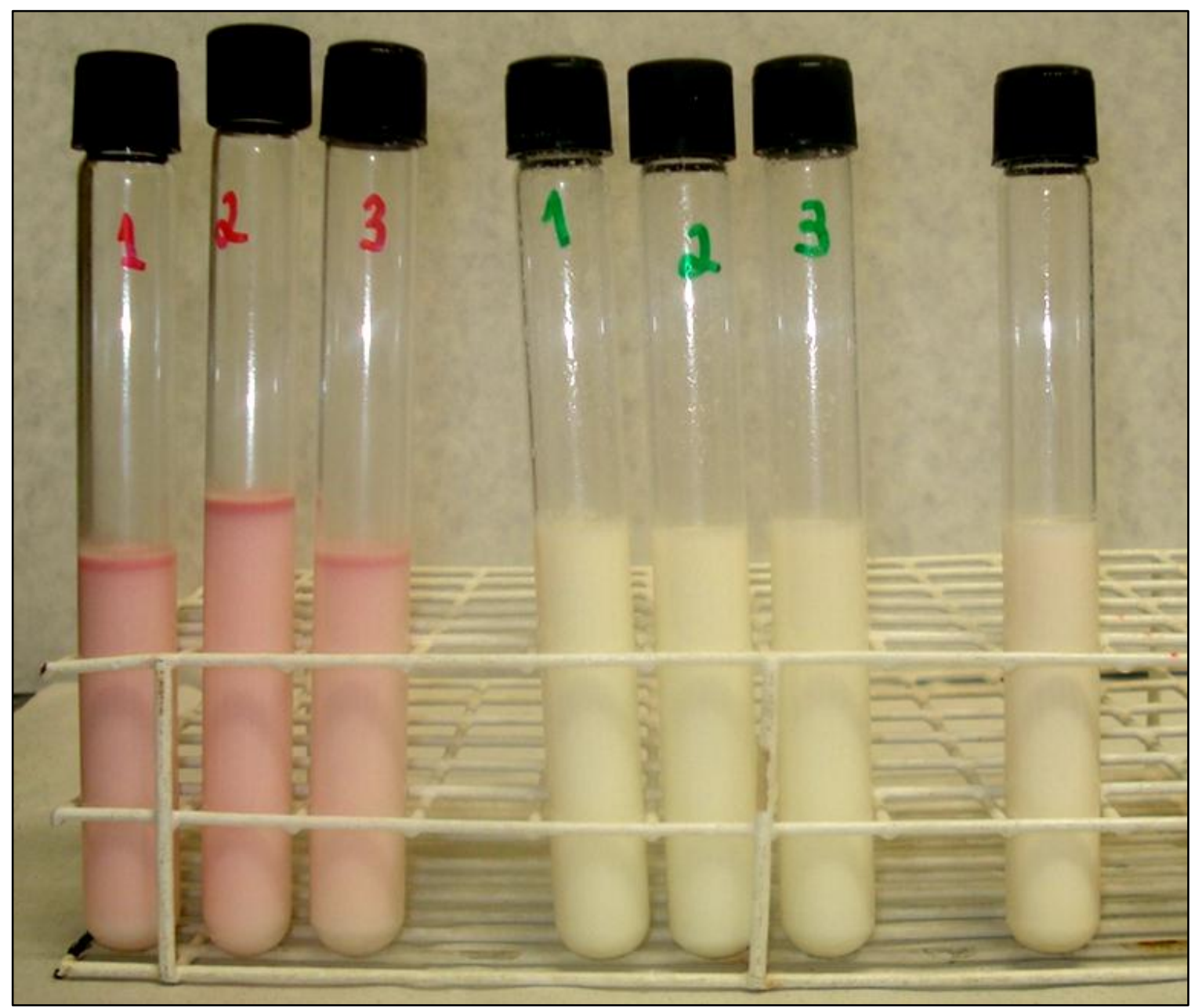

Figura 1 - Teste de redução do TTC ("tetra-test") com apenas 30 min após o início, comparando-se ambas as séries das mesmas amostras - "contaminantes Gram $(+)$ " e "psicrotróficos", juntamente com o branco da reação.

Das 370 amostras que apresentaram redução para Gram (+), $208(56,2 \%)$ constituíram-se de microbiota mista, isto é, sem o predomínio de grupos fisiológicos específicos; entretanto, $159(43,0 \%)$ evidenciaram claro predomínio de aeróbios estritos e apenas três $(0,8 \%)$ tiveram predomínio de anaeróbios - representados por crescimento e redução do TTC apenas na superfície ou no fundo do tubo, respectivamente.

Das 362 amostras que mostraram redução para microbiota Gram- ou "psicrotrófica", 321 $(88,7 \%)$ foram inespecíficas e compostas de microbiota mista, $23(6,3 \%)$ evidenciaram claro predomínio de aeróbios e 18 (5,0\%) tiveram predomínio de metabolismo anaeróbio.

Notou-se que, enquanto o predomínio de anaeróbios foi praticamente insignificante na microbiota Gram+, apenas $0,8 \%$ das amostras, esse grupo cresceu em importância na microbiota Gram-, passando a representar 5,0\% das amostras. O raciocínio inverso também foi verdadeiro, isto é, houve claro predomínio de aeróbios entre os Gram+ $(43,0 \%)$, declinando de importância entre os Gram-, apenas $6,3 \%$.

Com relação ao tempo de redução para a microbiota Gram+ observou-se que, das 370 amostras que apresentaram redução, 80 (21,4\%) reduziram o TTC em até 30 minutos, $154(41,2 \%)$ reduziram em até 1 hora, $211(56,4 \%)$ reduziram em até 2 horas e, com 3 horas após o início do teste, 249 ou $67,3 \%$ das amostras já apresentavam redução.

Quanto à possível pré-seleção de psicrotróficos em leite refrigerado, das 80 amostras que reduziram o TTC em até 30 minutos, apenas três $(3,7 \%)$ evidenciaram seleção. Das 154 que reduziram em até 1 hora, apenas $16(10,4 \%)$ evidenciaram seleção; das 211 amostras que reduziram em até 2 horas, $56(26,5 \%)$ evidenciaram e das 324 amostras que reduziram em até 5 horas, 249 (76,8\%) também apresentaram a presença de psicrotróficos.

Com relação ao tempo de redução para a microbiota Gram-, observou-se que, das 362 
amostras que apresentaram redução, três $(0,8 \%)$ reduziram em até 30 minutos, $16(4,3 \%)$ reduziram em até 1 hora, $56(15 \%)$ reduziram em até 2 horas e, com 3 horas após o início do teste, 123 ou (34\%) das amostras já apresentavam redução.

Do exposto e para as condições avaliadas, pode-se constatar que os microrganismos psicrotróficos: (1) ainda não se constituíram nos deteriorantes principais do leite cru refrigerado; (2) podem se constituir como deteriorantes principais em até $26,5 \%$ das amostras; mas (3) estão presentes em $76,8 \%$ das amostras. SOARES et al. (2008) demonstraram uma correlação de $r=0,98$ entre a contagem padrão em placas e a contagem em placas de psicrotróficos, comprovando o fato de que a maioria dos psicrotróficos enumerados é, na verdade, constituída de mesófilos que se adaptaram às condições de refrigeração.

Os dados obtidos por IZIDORO (2008) indicam rápida multiplicação, de $1,7 \log _{10}$, e intenso metabolismo lipoproteolítico da microbiota psicrotrófica em leites crus estocados em temperaturas de resfriamento clássico. Entretanto, é importante ressaltar que este trabalho focou um momento anterior da produção e foi realizado em temperaturas controladas em laboratório.

No trabalho realizado por SOARES et al. (2008), das amostras com contagem de psicrotróficos acima de $10^{7} \mathrm{UFCmL}^{-1}, 81,8 \%$ e $94,5 \%$ foram identificadas pelo teste rápido em tubos após 4 e 6 horas de incubação, respectivamente.

DIAS et al. (2007), avaliando a influência da temperatura de estocagem do leite cru, observaram que $55 \%$ das amostras apresentavam contagem bacteriana total acima dos limites permitidos pela IN 51 e que, dessas, $65 \%$ eram provenientes de tanques de expansão coletivos.

LORENZETTI (2006), realizando o teste da redutase em amostras de leite cru de duas regiões, observou diferenças nos resultados, sendo que uma região apresentou tempo de redutase de 274,8 minutos $(>4,5 \mathrm{~h})$ e a outra região 137,2 minutos $( \pm 2,5 \mathrm{~h})$, caracterizando as duas regiões dentro dos padrões normais para essa prova. Sabe-se, entretanto, que os testes de redução, seja do azul de metileno ou da rezasurina, realizados da mesma forma que eram no passado, não possuem a mesma eficácia para apontar problemas microbiológicos em leite refrigerado, situação bem documentada na literatura internacional. Nesse aspecto, todas as amostras coletivas submetidas à prova de redução do azul de metileno, ainda nos laticínios de origem, apresentaram tempo de redução sempre maior que 2 horas.

No entanto, utilizando-se o "Tetra-test" para avaliar a qualidade do leite cru, existe também a possibilidade de se caracterizar o tipo de microrganismos predominante em cada amostra ("contaminantes" ou "psicrotróficos"), permitindo a tomada de decisões para corrigir problemas higiênico-sanitários e de manejo.

Os baixos tempos de redução do TTC observados, denotando elevada carga microbiana das amostras, podem estar associados tanto à refrigeração marginal, choque térmico por adição de leite não refrigerado de uma nova ordenha e à utilização dos tanques comunitários. De acordo com os dados obtidos por DIAS et al. (2007), nos tanques que armazenam leite de apenas um produtor a qualidade microbiológica do produto geralmente é melhor, pois o leite é acondicionado de uma só vez, evitando as elevações temporárias de temperatura que favorecem a multiplicação microbiana, como ocorrem em tanques coletivos. Além disso, as condições de higiene na obtenção também podem ser mais bem controladas.

Apesar de as amostras coletivas (bocas de tanques) apresentarem resultado negativo para a pesquisa de antibióticos pelo Charm-test, quatro amostras de produtores não apresentaram redução em 24 horas em ambas as provas (Gram + e Gram -) e outras oito não reduziram para Gram-, possivelmente denotando a presença de inibidores. As quatro amostras que não reduziram em ambos os testes evidenciaram ausência de fosfatase alcalina, denotando prévio tratamento térmico do leite. Todas elas evidenciaram proteólise elevada, condição que poderia qualificá-las como suspeitas e positivas para fraude por adição de soro de queijo.

As 374 amostras individuais deram origem a 125 amostras de boca de tanque, representando média de três produtores por boca, embora, na realidade, esse número tenha variado entre um e oito produtores. A estimativa da contagem total de microrganismos aeróbios (CBT) evidenciou a frequência com intervalos apresentados na Tabela 2.

Apenas nove $(7,2 \%)$ das amostras apresentaram contagens inferiores a $1,0 \times 10^{6} \mathrm{UFCmL}^{-1}$, mesmo assim incluindo uma amostra que não apresentou redução em $24 \mathrm{~h}$, com fosfatase alcalina negativa e elevado índice de proteólise.

Assim, 92,8\% evidenciaram contagens superiores ao limite, com $71,2 \%$ configurando leites de qualidade ruim e muito acima do estabelecido pela IN 51, concordando com os resultados obtidos por NERO et al. (2005). Índices elevados de amostras com contagens acima do padrão também foram relatados por DIAS et al. (2007). Todos esses dados permitem afirmar que existem sérias dificuldades de adaptação às condições impostas pela IN 51, com grande quantidade de leite de qualidade ruim nas mais variadas regiões do Brasil. 
TABELA 2. Número e respectiva porcentagem de amostras de conjunto (bocas de tanque de veículo transportador) de acordo com a estimativa de microrganismos mesófilos aeróbios e facultativos viáveis (CPP), em seus respectivos intervalos de contagem

\begin{tabular}{lcc}
\hline $\mathrm{CPP}\left(\mathrm{UFC} \mathrm{mL}^{-1}\right)$ & Número de amostras & Porcentagem $(\%)$ \\
\hline$<1,0 \times 10^{3}$ & 0 & 0,0 \\
$1,0 \times 10^{3} \mathrm{a}<1,0 \times 10^{4}$ & 1 & 0,8 \\
$1,0 \times 10^{4} \mathrm{a}<1,0 \times 10^{5}$ & 2 & 1,6 \\
$1,0 \times 10^{5} \mathrm{a}<1,0 \times 10^{6}$ & 6 & 4,8 \\
$1,0 \times 10^{6} \mathrm{a}<1,0 \times 10^{7}$ & 27 & 21,6 \\
$1,0 \times 10^{7} \mathrm{a}<1,0 \times 10^{8}$ & 49 & 39,2 \\
$1,0 \times 10^{8} \mathrm{a}<1,0 \times 10^{9}$ & 38 & 30,4 \\
$>1,0 \times 10^{9}$ & 2 & 1,6 \\
\hline Total & 125 & 100,0 \\
\hline
\end{tabular}

A Tabela 3 mostra a relação entre os intervalos de contagem das 125 amostras de conjunto e a quantidade de amostras individuais (produtores) que reduziram o TTC. Pôde-se observar que quanto mais elevada a contagem em placas, maior o número de amostras que reduziram o TTC e menor o tempo de redução dessas amostras, o que reforça a caracterização de uma grande quantidade de leite de má qualidade, boa correlação entre essas provas e a eficácia do "Tetra-test" na predição rápida da qualidade microbiológica da matéria-prima.

TABELA 3. Relação entre os intervalos de contagem padrão em placas das amostras de conjunto (bocas dos veículos transportadores) e o respectivo número de amostras de produtores que reduziram o TTC em cada faixa de tempo avaliada

\begin{tabular}{|c|c|c|c|c|c|c|c|c|c|}
\hline \multirow{2}{*}{$\begin{array}{l}\text { Intervalo CPP } \\
\left(\mathrm{UFC}_{\mathrm{mL}}^{-1}\right)\end{array}$} & \multicolumn{9}{|c|}{ Tempo de Redução do TTC } \\
\hline & $15 \mathrm{~min}$ & $30 \mathrm{~min}$ & $1 \mathrm{~h}$ & $2 \mathrm{~h}$ & $3 \mathrm{~h}$ & $4 \mathrm{~h}$ & $5 \mathrm{~h}$ & $24 \mathrm{~h}$ & NR \\
\hline $1,0 \times 10^{3}$ a $<1,0 \times 10^{4}$ & --- & --- & $\begin{array}{ll}-- \\
-1\end{array}$ & $\overline{---}$ & --- & --- & --- & 1 & --- \\
\hline $1,0 \times 10^{4} a<1,0 \times 10^{5}$ & --- & --- & --- & --- & --- & --- & --- & 1 & 1 \\
\hline $1,0 \times 10^{5} a<1,0 \times 10^{6}$ & --- & --- & --- & --- & 1 & 1 & 3 & 1 & --- \\
\hline $1,0 \times 10^{6}$ a $<1,0 \times 10^{7}$ & 2 & 4 & 8 & 2 & 7 & 3 & 1 & --- & --- \\
\hline $1,0 \times 10^{7}$ a $<1,0 \times 10^{8}$ & 6 & 24 & 12 & 5 & 1 & 1 & --- & --- & --- \\
\hline $1,0 \times 10^{8}$ a $<1,0 \times 10^{9}$ & 10 & 12 & 12 & 4 & --- & --- & --- & --- & --- \\
\hline$>1,0 \times 10^{9}$ & --- & --- & 2 & --- & --- & --- & --- & --- & --- \\
\hline Total & 18 & 40 & 34 & 11 & 9 & 5 & 4 & 3 & 1 \\
\hline
\end{tabular}

Pelos dados das Tabelas 2 e 3, pode-se observar que uma porcentagem pequena das amostras de conjunto (nove ou 7,2\%) satisfez o padrão microbiológico estabelecido. $\mathrm{O}$ restante, $92,8 \%$, foi representado por leite de qualidade microbiológica ruim e péssima. Considerando-se que essas amostras se referem ao leite de conjuntos de produtores (bocas de tanque) englobando as amostras analisadas de produtores, isso demonstra que os resultados obtidos com o "Tetra-test" são perfeitamente aceitáveis, não havendo discrepância entre os resultados.

As 125 amostras foram submetidas também à determinação do índice de refração, com o objetivo de verificar possível adição de água ao leite. Apesar de não acusadas na prova de crioscopia realizada na recepção do leite nas indústrias, três amostras $(2,4 \%)$ acusaram a presença de água adicionada, em proporções estimadas entre 3 e $6 \%$.

Das 125 amostras, 24 (19,2\%) apresentaram níveis anormais de proteólise da $\kappa$-caseína, superiores aos esperados para leite normal de conjunto adequadamente conservado. Isso é preocupante quando se verifica que se referem a grandes quantidades de leite, oriundas da mistura de vários produtores, cuja tendência da média seria a de se aproximar da normalidade. Tais níveis, quando comparados à fraude por adição de soro, 
classificariam seis dessas amostras $(25,0 \%)$ como francamente positivas ou adulteradas e as demais 18 $(75,0 \%)$ como suspeitas, demandando providências no sentido de aclarar seus motivos (FUKUDA et al., 2004). Os dados obtidos por IZIDORO (2008) tornam possível a hipótese de que esse alto grau de proteólise possa estar associado a resfriamento inadequado ainda na propriedade.

\section{CONCLUSÕES}

O "Tetra-test" mostrou-se eficaz como ferramenta de seleção da matéria-prima recebida pela indústria, permitindo uma avaliação (screening) da qualidade microbiológica do leite cru e possibilitando especificar a provável causa ou origem dos defeitos detectados, havendo correspondência com a qualidade avaliada por metodologia oficial e vantagens inequívocas em relação à Redução do Azul de Metileno. Desse modo, seus resultados podem ser utilizados como ferramenta de gestão, seja na própria seleção ou, principalmente, dirigindo soluções e medidas corretivas para os problemas de qualidade apontados. Mostrou que os microrganismos capazes de adaptação psicrotrófica ainda não se configuram como deteriorantes principais do leite cru refrigerado, mas se encontravam presentes em 76,8\% das amostras, podendo ser responsabilizados como deteriorantes principais em apenas $26,5 \%$ dos casos.

Verificou-se, ainda, que o leite cru refrigerado de grande parte dos fornecedores não atende aos requisitos exigidos pela Instrução Normativa 51, com 211 amostras $(56,4 \%)$ classificadas como de qualidade ruim, confirmadas pela CBT das amostras das respectivas bocas de tanques do veículo transportador.

\section{REFERÊNCIAS}

APHA. Standard Methods for the Examination of Dairy Products. 2004. H. Michael Wehr and Joseph F. Frank Editors $\left(17^{\text {th }}\right.$ Ed.), 570p. American Public Health Association.

ARCURI, E. F.; SILVA, P. D. L.; BRITO, M. A. V. P.; BRITO, J. R. F.; LANGE, C. C.; MAGALHÃES, M. M. A. Contagem, isolamento e caracterização de bactérias psicrotróficas contaminantes de leite cru refrigerado. Ciência Rural, v.38, n.8, 2250-2255, nov, 2008.

BELOTI, M. V.; BARROS, M. A. F.; NERO, L. A.; PACHEMSHY, J. A. S.; SANTANA, E. H. W.; FRANCO, B. D. G. M. Quality of pasteurized milk influences the performance of ready-to-use systems for enumeration of aerobic microorganisms. International Dairy Journal, v.12, n.5, p. 413-418. 2002.
BRASIL. Instrução Normativa ${ }^{\circ} 51$ de 18 de setembro de 2002. Regulamentos técnicos de produção, identidade, qualidade do leite tipos A, B e C, da identidade e qualidade do leite cru refrigerado e pasteurizado e da coleta de leite cru refrigerado e de seu transporte a granel. Diário Oficial [da] União, Brasília, 20 set. 2002. Seção 1, n. 183 , p. 13-22.

BRASIL. Instrução Normativa $\mathrm{n}^{\circ} 68$ de 12 de dezembro de 2006. Métodos Analíticos Oficiais Físico-Químicos, para Controle de Leite e Produtos Lácteos. Diário Oficial [da] União, Brasília, 14 dez. 2006. Seção 1.

DIAS, D. T.; AVANÇO, S. V.; PONSANO, E. H. G. Influência da temperatura de refrigeração sobre a qualidade microbiológica de leite cru. Higiene Alimentar, São Paulo, v.21, n. 150, p. 226-227, 2007.

FUKUDA, S. P., RÖIG, S. M. \& PRATA, L. F. Correlation between acidic ninhydrin and HPLC methods to evaluate fraudulent addition of whey in milk. Lait, v.84, p. 501-512. 2004.

IZIDORO, T. B. Efeito da multiplicação de microrganismos psicrotróficos sobre as características físico-químicas do leite cru. 2008. 94f. Dissertação (Mestrado) -Faculdade de Medicina Veterinária e Zootecnia, Universidade Estadual Paulista, Botucatu, $2008 . \quad$ Disponível em: http://www.athena.biblioteca.unesp.br/exlibris/bd/bbo/330 04064022P3/2008/izidoro_tb_me_botfmvz.pdf. Acesso em: 24 de maio de 2012.

LORENZETTI, D. K. Influência do tempo e da temperatura no desenvolvimento de microrganismos psicrotróficos no leite cru de dois estados da região sul. 2006. 71f. Dissertação (Mestrado)- Universidade Federal do Paraná - Curitiba. Disponível em: http://dspace.c3sl.ufpr.br/dspace/bitstream/handle/1884/41 15/DAYANE\%20KARINA\%20LORENZETTI.pdf;jsessi onid=CAB4CB678724D5DEDC3D0A6CA4F21D49?seq uence $=1$. Acesso em: 24 de maio de 2012.

MAHMOUD, N. S. \& GHALY, A. E. Influence of Temperature and $\mathrm{pH}$ on the Nonenzymatic Reduction of Triphenyltetrazolium Chloride. Biotechnology Progress, v. 20, n.1, p. 346-353. 2004.

MARTINS, M. E. P.; NICOLAU, E. S.; MESQUITA, A. J.; NEVES, R. B. S.; ARRUDA, M. L. T. Qualidade do leite cru produzido e armazenado em tanques de expansão no Estado de Goiás. Ciência Animal Brasileira, v. 9, n. 4, p. 1152-1158, out./dez. 2008.

NERO, L. A.; MATTOS, M. R.; BELOTI, V.; BARROS, M. A. F.; PINTO, J. P. A. N.; ANDRADE, N. J.; SILVA, W. P.; FRANCO, B. D. G. M. Leite cru de quatro regiões leiteiras brasileiras: Perspectivas de atendimento dos requisitos microbiológicos estabelecidos pela Instrução Normativa 51. Ciência e Tecnologia de Alimentos, Campinas, v. 25, p. 191-195, 2005.

PRATA, L. F. Teste rápido para avaliação da qualidade microbiológica do leite cru refrigerado. Revista Indústria de Laticínios Cândido Tostes, v. 12, n. 68, p. 63-66, 
2007.

SANTANA, E. H. W.; BELOTI, V.; BARROS, M. A. F.; MORAES, L. B.; GUSMÃO, V. V.; PEREIRA, M. S. Contaminação do leite em diferentes pontos do processo de produção: I. Microrganismos aeróbios mesófilos e psicrotróficos. Semina: Ciências Agrárias, v. 22, n.2, p. 145-154, jul./dez. 2001.

SOARES, P. V., PRATA, L. F., ALMEIDA, A. O.
Estimativa rápida da carga de microrganismos psicrotróficos em leite cru refrigerado. Revista Indústria de Laticínios, v.13, n. 72, p. 56-64. 2008.

VALLIN, V. M.; BELOTI, V.; BATTAGLINI, A. P. P.; TAMANINI, R.; FAGNANI, R.; ANGELA, H. L.; SILVA, L. C. C. Melhoria da qualidade do leite a partir da implantação de boas práticas de higiene na ordenha em 19 municípios da região central do Paraná. Semina: Ciências Agrárias, v. 30, n. 1, p. 181-188, jan./mar. 2009.

Protocolado em: 02 jan 2010. Aceito em:09 ago. 2012. 